\title{
Brain-Derived Neurotrophic Factor in Infants $<32$ Weeks Gestational Age: Correlation With Antenatal Factors and Postnatal Outcomes
}

\author{
RAKESH RAO, CHARLES B. MASHBURN, JINGNAN MAO, NITIN WADHWA, GEORGE M. SMITH, AND NIRMALA S. DESAI \\ Department of Pediatrics [R.R., J.M.], Washington University of St. Louis, St. Louis, Missouri 63110; Department of Physiology [C.B.M., \\ G.M.S.], Department of Pediatrics [N.S.D.], University of Kentucky, Lexington, Kentucky 40506; Regional Medical Center [N.W.], \\ Madisonville, Kentucky 42431
}

\begin{abstract}
Neurotrophins (NTs) play important roles in brain growth and development. Cord blood (CB) brain-derived neurotrophic factor (BDNF) concentrations increase with gestational age but data regarding postnatal changes are limited. We measured BDNF concentrations after birth in 33 preterm infants $<32$-wk gestation. Serum was collected at birth (CB), at day 2, between day 6 and 10 (D6), at day 30 (D30), and at day 60 (D60). BDNF concentrations fell on $\mathrm{D} 2(p=0.03)$, recovered by D6 $(p=0.10)$, and continued to rise thereafter at D30 $(p=0.06)$ and D60 $(p=0.01)$ compared with CB. $\mathrm{CB}$ BDNF concentrations positively correlated with duration of rupture of membranes $(r=0.43, p=0.04)$. Antenatal steroids (ANS, $p=0.02$ ), postnatal steroids (PNS, $p=0.04$ ), and retinopathy of prematurity (ROP, $p=0.02$ ) were identified as significant factors in multivariate analyses. The median (25-75th interquartile range) $\mathrm{CB}$ BDNF concentrations were higher in infants who received a complete course ANS compared with those who received a partial course [1461 (553-2064) versus 281 (171-536) pg/mL, $p=0.04]$. BDNF concentrations negatively correlated with the use of PNS at D30 ( $r=$ $-0.53, p=0.002)$ and at D60 $(r=-0.55, p=0.009)$. PNS use was associated with reduced concentrations of BDNF at D30 [733 (1011983 ) versus $2224(1677-4400) \mathrm{pg} / \mathrm{mL}, p=0.004]$ and at D60 [1149 (288-2270) versus 2560 (1337-5166) pg/mL, $p=0.01]$. BDNF concentrations on D60 in infants who developed ROP $(n=16)$ were lower than those who did not develop ROP $(n=7)$ [1417 (553-2540) versus $3593(2620-7433) \mathrm{pg} / \mathrm{mL}$, respectively, $p=0.005]$. Our data suggests that BDNF concentrations rise beyond the first week of age. BDNF concentrations correlate with factors that influence neurodevelopment outcomes. (Pediatr Res 65: 548-552, 2009)
\end{abstract}

$\mathrm{N}^{\mathrm{en}}$ eurotrophins (NTs) - nerve growth factor, brain-derived neurotrophic factor (BDNF), NT-3, and NT-4/5-are a family of growth factors that play an important role in the growth and development of central and peripheral nervous systems $(1,2)$. NTs promote the growth, survival, proliferation, and migration of neurons; regulate neurotransmitter synthesis and secretion; and the development of synaptic plasticity. In addition, they also modulate immune cells (3-6). NTs are also protective against apoptotic neuronal loss, and exogenous BDNF administration has been shown to attenuate various forms of brain injury in both animals and humans (7-9).

Received October 2, 2008; accepted December 20, 2008.

Correspondence: Rakesh Rao, M.D., Division of Newborn Medicine, Campus Box 8116, 660 South Euclid, St. Louis, MO 63110; e-mail: Rao_R@kids.wustl.edu Supported by NIH/NINDS grant R01 NS040592 (G.M.S.).
BDNF is synthesized in several neuronal and glial cell populations and also expressed in several nonneural tissues, such as immune cells and the vascular endothelium, but the contribution of the latter to the circulating pool is limited (10-14). NTs cross the blood-brain barrier that is relatively immature in the preterm infants $(15,16)$. Karege et al. (17) have shown that changes in serum BDNF concentrations are similar to changes in BDNF concentrations in the brain. In addition to its local effects in the central and peripheral nervous systems, BDNF plays important roles in several nonneural tissues (18-21). For example, exogenous BDNF administration has been shown to modulate glucagon secretion and glucose homeostasis (22). Changes in BDNF concentrations also correlate with disease course and response to therapy under various clinical conditions (6,23-26).

Prematurity is associated with increased morbidity and mortality and outcomes are influenced by both antenatal and postnatal factors (27-30). Preterm brain cortical volume grows nearly 4-fold between 29 and 35 weeks of gestation and is a critical period for neuronal growth and migration. Infants born at this gestation period have been shown to have decreased cortical gray and white matter at term equivalentsecondary to apoptosis and neuronal atrophy - that impacts on long-term neurodevelopmental outcomes (31-33).

There is little data regarding BDNF during this critical period of neuronal growth, especially in preterm infants. BDNF concentrations are lower in preterm infants compared with term and both are decreased compared with adults (3436). Cord blood (CB) BDNF concentrations increase with gestational age (GA) and with use of antenatal steroids (ANS), whereas low concentrations have been associated with intraventricular hemorrhage (IVH) (36). BDNF concentrations in cerebrospinal fluid are increased in infants with perinatal depression and meningitis $(37,38)$. In both animal models and humans, BDNF concentrations are decreased in infections $(39,40)$. There is little data in preterm infants regarding changes in BDNF concentrations after birth, or its relationship with factors that influence neurodevelopmental outcomes. Be-

\footnotetext{
Abbreviations: ANS, antenatal steroids; BDNF, brain-derived neurotrophic factor; IVH, intraventricular hemorrhage; NTs, neurotrophins; PNS, postnatal steroids; ROP, retinopathy of prematurity
} 
cause ANS improve neurodevelopmental outcomes (28) and increase BDNF concentrations (36), and postnatal steroids (PNS) are detrimental to the developing brain (41), we hypothesized that BDNF concentrations would be decreased by PNS use. In this study, we measured serial BDNF concentrations from birth until discharge in preterm infants $<32$-wk gestation. Further, we sought to correlate BDNF concentrations with other factors, such as birth weight and gestational age, and with clinical morbidities, such as IVH, bronchopulmoary dysplasia (BPD), and necrotizing enterocolitis (NEC), which are known to influence outcomes after premature birth.

\section{MATERIALS AND METHODS}

The study was approved by the University of Kentucky (UK) Institutional Review Board and written informed consent was obtained from all parents. Parents were free to withdraw their infant from the study at any time during their infant's stay in the neonatal intensive care unit (NICU).

Study design and population. The study was conducted prospectively over a 1-y-period at the UK NICU. Fifty infants $<32$ wk were enrolled. Infants with known congenital anomalies or in the absence of informed consent were excluded.

Data collection and analyses. CB was collected aseptically at delivery as reported previously (36). Serial samples were collected on day 2 (D2), between days 6 and 10 (D6), at day 30 (D30), and at day 60 (D60) of life. At the time of medically indicated blood draw, an additional $0.5 \mathrm{~mL}$ blood was collected, serum separated, and stored at $-80^{\circ} \mathrm{C}$ until analyses.

BDNF assay was determined using DuoSet ELISA kits (R\&D Systems, Minneapolis, MN) according to manufacturer's instructions. The minimum detection limit of this assay is $23.4 \mathrm{pg} / \mathrm{mL}$ (sensitivity) and there is no cross reactivity with other NTs, i.e. $\beta$-nerve growth factor, GDNF, NT-3, or NT-4 at $50 \mathrm{ng} / \mathrm{mL}$. The interassay and intraassay coefficient of variation were 8.0 and $6.2 \%$, respectively. Preliminary assays were done to determine ideal dilutions to achieve assay results within the standardized range. All samples were run in triplicate.

Clinical data. Antenatal data including maternal age, gravida, race, smoking, chorioamnionitis (42), premature rupture of membranes (ROM) (43), duration of ROM, and antenatal steroid use for lung maturation (defined as complete if two doses of betamethasone $24 \mathrm{~h}$ apart or four doses of dexamethasone every $12 \mathrm{~h}$ in a 48-h period were given before delivery, or partial or none) (44); and neonatal characteristics of birth weight, gender, and GA $(45,46)$ were recorded. Clinical morbidities of grades of IVH $(47)$, BPD (oxygen dependency at 36-wk postmenstrual age) (48), NEC (Bell's stage 2 or higher) (49), retinopathy of prematurity (ROP) (50), and sepsis (defined by positive blood culture), and the use of systemic PNS were recorded.

Statistical analyses. Descriptive analysis was used to describe changes in BDNF concentrations at different time points, and median, interquartile range, reported. Wilcoxon test was used to test the differences in BDNF concentrations between clinical outcome groups. Pearson and Spearman correlation were used to describe the relationship between BDNF concentrations at different time points and clinical outcomes. Two-way analysis of variance with contrast analyses was used to determine the changes in BDNF concentrations along time, and the difference among the time points and clinical outcomes. Multivariate analyses were carried out to determine significant clinical factors for BDNF concentration changes with time. All data were analyzed using SAS 9.0 statistical software. A $p$ value $<0.05$ was considered significant. BDNF concentrations are reported as median (25-75th interquartile range).

\section{RESULTS}

Outcomes of enrollment. Of the 50 infants enrolled, seven died before the end of first week of life, three gave consent only for $\mathrm{CB}$ collection, and four parents withdrew consent after initial samples were drawn. In three infants, serial samples could not be collected at appropriate times and therefore excluded from analyses.

Missing data. CB samples were not always available as some infants were transferred after birth. In some, clinical condition (six infants on D2, five on D6), technical reasons (one on D6, one on D30), and discharge home (two on D30 and 10 on D60) precluded sample collection. We present data from patients where at least three serial samples beyond the first week of life were available $(n=33)$. Samples were available for $\mathrm{CB}(n=22)$, D2 $(n=27)$, D6 $(n=27), \mathrm{D} 30$ $(n=30)$, and D60 $(n=23)$.

Serial changes in BDNF. The clinical and demographic features are presented in Table 1. BDNF concentrations were 1099 (374-2035), 46 (23-347), 1857 (678-2721), 1957 (1271-2669), and 2339 (941-3425) pg/mL in CB, on D2, D6, D30, and D60, respectively.

After birth, there was a transient decline in BDNF concentrations followed by recovery between 6 and $10 \mathrm{~d}$ of life (Fig. $1)$. BDNF concentrations on $\mathrm{D} 2$ were significantly lower than $\mathrm{CB}(p=0.03)$, and at D6, D30, and D60 $(p<0.001$ for all comparisons). BDNF concentrations recovered by D6 ( $p=$ $0.10)$ and continued to rise at D30 $(p=0.06)$ and D60 ( $p=$ $0.01)$ compared with $\mathrm{CB}$. There were no differences between D30 and D60 BDNF concentrations.

BDNF and antenatal factors. CB BDNF concentrations correlated with duration of ROM $(r=0.43, p=0.04)$. CB BDNF concentrations (but not at other time points) were significantly higher in infants who received a complete course of ANS $(n=16)$ compared with those $(n=6)$ who had received a partial course of ANS [1461 (553-2064) versus 281

Table 1. Antenatal clinical features and postnatal outcomes of the study population

\begin{tabular}{|c|c|}
\hline Antenatal data & $n=33(\%)$ \\
\hline \multicolumn{2}{|l|}{ Maternal race } \\
\hline White & $26(78.8)$ \\
\hline Black & $3(9.1)$ \\
\hline Other & $4(12.1)$ \\
\hline Gender, female/male & $19(57.6) / 14(42.4)$ \\
\hline Chorioamnionitis & $4(12.1)$ \\
\hline PROM & $9(27.3)$ \\
\hline Duration of ROM (in h)* & $1(1-57.0)$ \\
\hline \multicolumn{2}{|l|}{ Antenatal steroids } \\
\hline None & $3(9.1)$ \\
\hline Partial & $6(18.1)$ \\
\hline Complete & $24(72.7)$ \\
\hline Smokers & $12(36.4)$ \\
\hline Maternal age, y & $24 \pm 6$ \\
\hline Gravida & $2.6 \pm 1.8$ \\
\hline Preeclampsia & $13(39.4)$ \\
\hline Gestational age, wk mean $\pm \mathrm{SD}$ & $27.4 \pm 2.1$ \\
\hline \multicolumn{2}{|l|}{ Neonatal outcomes } \\
\hline Birth weight, $g$ mean $\pm \mathrm{SD}$ & $833 \pm 271$ \\
\hline \multicolumn{2}{|l|}{ IVH } \\
\hline Grade I-II & $12(36.4)$ \\
\hline Grade III-IV & $0(0)$ \\
\hline NEC & $3(9.1)$ \\
\hline BPD & $22(66.7)$ \\
\hline ROP & $16(48.5)$ \\
\hline Surgical $\mathrm{ROP} \dagger$ & $5(15.1)$ \\
\hline PNS & $7(21.2)$ \\
\hline Sepsis & $11(33.3)$ \\
\hline $\begin{array}{l}\text { Median age at diagnosis of first episode } \\
\text { of sepsis (d)* }\end{array}$ & $14(9-20)$ \\
\hline Median number of episodes of sepsis* & $1(1-2)$ \\
\hline
\end{tabular}

For duration of ROM, those ruptured at delivery were assigned a value of 1 .

* Data shown are median (25-75th interquartile range).

$\dagger$ Stage 3 or higher and required surgical intervention. 


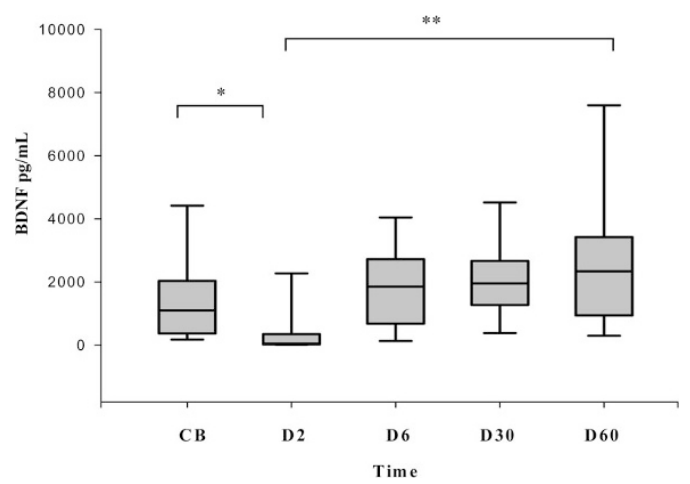

Figure 1. Serial changes in BDNF concentrations in preterm infants $<32$-wk gestation. Box plots showing that BDNF concentrations decline at D2 compared with cord blood but continue to rise thereafter. BDNF concentrations at D2 were significantly lower than at all other times $(* p=0.03, * * p<0.001$ for all comparisons). Data are shown as median (25-75th interquartile range).

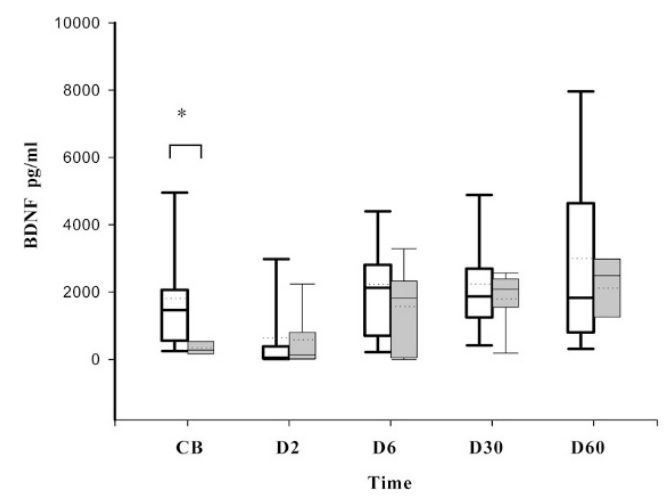

Figure 2. Effect of ANS on BDNF concentrations. Box plots showing BDNF concentrations at various time points in infants who received ANS (white) and those who did not receive ANS (gray). Data are shown as median (25-75th interquartile range). The dotted line in the box plots represents the mean value $\left({ }^{*} p=0.04\right)$.

(171-536) $\mathrm{pg} / \mathrm{mL}, p=0.04$, Fig. 2]. CB was not available for the three infants who had received no ANS.

CB BDNF concentrations did not correlate with birth weight, GA, or any other antenatal or maternal factors.

BDNF and postnatal outcomes. CB BDNF concentrations did not correlate with IVH $(r=-0.19, p=0.40)$ although they were lower in infants who developed IVH $(n=7)$ compared with those who did not develop IVH $[n=12,694$ (344-1337) versus 1473 (375-2057) $\mathrm{pg} / \mathrm{mL} ; p=0.36]$. IVH developed in 12 infants (grade I-II) with no infants with grades III or IV hemorrhage. Nine of 12 infants who developed IVH had received ANS, whereas the three infants who had not received any ANS all developed IVH.

BDNF concentrations were negatively correlated with the use of PNS $(r=-0.53, p=0.002)$ at D30 and at D60 $(r=$ $-0.55, p=0.009)$.

In infants who received PNS $(n=7)$ for either hypotension or chronic lung disease, BDNF concentrations were significantly decreased at D30 and at D60 (Fig. 3). BDNF concentrations at D30 were 733 (101-1983) versus 2224 (1677$4400) \mathrm{pg} / \mathrm{mL}(p=0.004)$ and at D60 were $1149(288-2270)$ versus $2560(1337-5166) \mathrm{pg} / \mathrm{mL}(p=0.01)$ in infants who did and did not receive PNS, respectively.

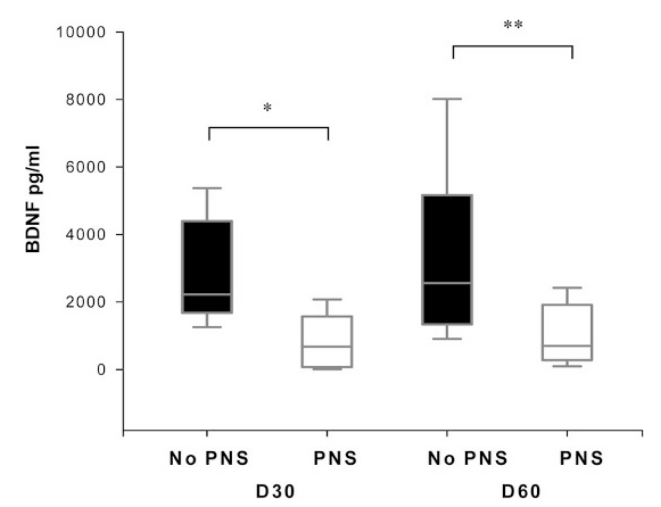

Figure 3. Effect of PNS on BDNF concentrations. Box plots showing that PNS use was associated with reduced BDNF concentrations at D30 $(* p=$ $0.004)$ and D60 $(* * p=0.014)$. Data are shown as median $(25-75$ th interquartile range).

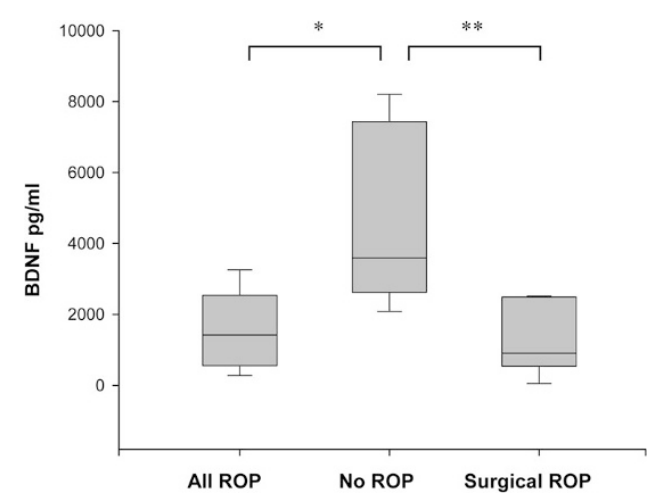

Figure 4. BDNF concentrations in infants with ROP at D60. Box plots showing that BDNF concentrations are reduced in infants with $\mathrm{ROP}(p<$ $0.005)$ and in infants with surgical ROP $(p=0.02)$ compared with infants with no ROP. Data are shown as median (25-75th interquartile range).

BDNF concentrations at D60 in infants who developed ROP $(n=16)$ versus those who did not develop ROP $(n=7)$ were 1417 (553-2540) versus $3593(2620-7433) \mathrm{pg} / \mathrm{mL}$, respectively ( $p=0.005$, Fig. 4). BDNF concentrations were significantly lower in those who required surgical intervention for stage 3 or higher ROP $(n=5)$ compared with those with no ROP [906 (538-2489) versus 3593 (2620-7433) pg/mL, respectively, $p=0.02]$. In infants with ROP, BDNF concentrations in those who required surgical intervention trended lower than those who did not require surgical intervention [906 (538-2489) versus 1417 (553-2540) $\mathrm{pg} / \mathrm{mL}, p=\mathrm{NS}$ ].

BDNF concentrations did not correlate with clinical outcomes of BPD, sepsis, and NEC.

Multivariate analyses. To determine significant factors that affected BDNF concentrations, multivariate analyses was carried out including each of the following covariates: GA, birth weight, smoking, ANS, IVH, BPD, ROP, NEC, sepsis, and PNS. In this model, both ANS $(p=0.02)$ and PNS $(p=0.04)$ and $\operatorname{ROP}(p=0.02)$ were identified as significant factors.

\section{DISCUSSION}

In this study, we have found that BDNF concentrations were correlated with factors known to be associated with deleterious developmental outcomes in preterm infants. To our knowledge, this is the first report of measured serial 
BDNF changes from birth until discharge in preterm infants less than 32-wk gestation.

BDNF is synthesized in several neuronal populations in central and peripheral nervous systems, vascular endothelium and immune cells $(12,13,51)$. Endogenous fetal synthesis, maternal passage, and placenta serve as source of BDNF in the fetus, although maternal and amniotic fluid levels of BDNF fall with advancing GA $(36,39,52-55)$. Abrupt removal of these sources could cause the sharp decline in BDNF levels after birth. The pattern of transient decline followed by rising levels is similar to that reported in term infants where BDNF concentrations fell on day 1 before rising on day 4 after birth (35), although in another study involving term and preterm infants, BDNF concentrations rose on day 1 in both groups but fell on day 4 only in preterm infants (34). In neither of these studies, BDNF concentrations were followed beyond the first week of age.

Use of ANS for pulmonary maturation are associated with improved neurodevelopmental outcomes in preterm infants (28). CB BDNF concentrations in this study were also significantly higher in infants whose mothers received a complete course of ANS (36). ANS-mediated neuroprotection may be through increased BDNF synthesis, or alternately, neuronal maturation after ANS may result in increased BDNF concentrations (36). Our data also suggests that the influence of ANS may last beyond birth, as BDNF levels were higher after the first week of age in infants who received a complete course. There was also no correlation between CB BDNF and IVH as reported previously (36). The higher antenatal steroid use and lack of any grade III or IV IVH in this study may explain these differences.

In contrast to ANS, PNS use was associated with significant attenuation in BDNF concentrations. PNS used for treatment of chronic lung disease has declined because of their detrimental effect on cortical brain growth (41). Corticosteroids inhibit cellular proliferation in the subventricular zone, downregulate BDNF synthesis, and decrease BDNF expression in the developing brain and after ischemic injury (56-59). BDNF expression is also attenuated in conditions of neuronal atrophy or cell death and aging (60). Because BDNF crosses the blood-brain barrier (14) and peripheral BDNF levels reflect central levels (17), lower BDNF levels associated with PNS could be a reflection of either a direct suppressive effect or neuronal apoptosis. BDNF also regulates neuronal migration (61) and Reelin expression-a metalloprotein that influences the "inside-out" layering during cortical migration (62). Similarly, BDNF is involved in synaptic development and plasticity associated with learning and memory (63). Alterations in BDNF concentrations after postnatal steroid use could therefore possibly affect migration of cortical neurons during this period of brain growth.

BDNF is expressed in the visual cortex and retina during development and plays an important role in development of visual plasticity $(64,65)$. We noted that BDNF concentrations were decreased in infants who developed ROP and trended lower in those with more severe ROP. ROP is characterized by abnormal neovascularization in which local concentrations of VEGF play a significant role in its pathogenesis (66). Conflicting data suggest that serum VEGF concentrations may be decreased or unchanged with severe ROP $(67,68)$. BDNF is expressed in the vascular endothelium, is involved in angiogenesis, and increases VEGF expression $(69,70)$. The presence of $\mathrm{BDNF}$ in the retina and its possible role in angiogenesis suggests that BDNF may play an as yet unappreciated role in the development of ROP. It remains to be determined whether low BDNF concentrations are a marker for severe ROP.

BDNF concentrations were positively correlated with duration of ROM in our study, which to the best of our knowledge has not been reported previously. Premature ROM increases risk of infections and can be considered a form of stress for the fetus (43). Alterations in expression of neuronal markers including decreased BDNF concentrations have been reported in animals exposed to prenatal stress and infections $(39,71,72)$. However, only four infants were diagnosed with chorioamnionitis that precluded further analyses in this study. The correlation of BDNF concentrations and duration of ROM may perhaps be related to exposure to ANS the majority of infants received before delivery.

The strengths of our study include the serial measurement of BDNF concentrations in preterm infants. Our results support strong correlation between BDNF concentrations and antenatal steroid use and postnatal factors of postnatal steroid use and severe ROP, all of which are known to influence neurodevelopmental outcomes.

In summary, BDNF concentrations rise following a transient decline after birth. BDNF concentrations were strongly correlated with several antenatal factors and postnatal outcomes that significantly impact neurodevelopmental outcomes in preterm infants. A larger study and developmental follow up of these infants would be required to further answer these questions.

Acknowledgment. We thank Dr. Nitin Chouthai for his technical expertise and guidance in the successful completion of this work.

\section{REFERENCES}

1. McAllister AK 2001 Neurotrophins and neuronal differentiation in the central nervous system. Cell Mol Life Sci 58:1054-1060

2. Ernfors P 2001 Local and target-derived actions of neurotrophins during peripheral nervous system development. Cell Mol Life Sci 58:1036-1044

3. Chao MV 2003 Neurotrophins and their receptors: a convergence point for many signalling pathways. Nat Rev Neurosci 4:299-309

4. Twiss JL, Chang JH, Schanen NC 2006 Pathophysiological mechanisms for actions of the neurotrophins. Brain Pathol 16:320-332

5. Hennigan A, O'Callaghan RM, Kelly AM 2007 Neurotrophins and their receptors: roles in plasticity, neurodegeneration and neuroprotection. Biochem Soc Trans 35:424-427

6. Schulte-Herbruggen O, Braun A, Rochlitzer S, Jockers-Scherubl MC, Hellweg R 2007 Neurotrophic factors-a tool for therapeutic strategies in neurological, neuropsychiatric and neuroimmunological diseases? Curr Med Chem 14:2318-2329

7. Miller FD, Kaplan DR 2001 Neurotrophin signalling pathways regulating neuronal apoptosis. Cell Mol Life Sci 58:1045-1053

8. Husson I, Rangon CM, Lelievre V, Bemelmans AP, Sachs P, Mallet J, Kosofsky BE, Gressens P 2005 BDNF-induced white matter neuroprotection and stage-dependent neuronal survival following a neonatal excitotoxic challenge. Cereb Cortex 15:250-261

9. Almli CR, Levy TJ, Han BH, Shah AR, Gidday JM, Holtzman DM 2000 BDNF protects against spatial memory deficits following neonatal hypoxia-ischemia. Exp Neurol 166:99-114

10. Karege F, Bondolfi G, Gervasoni N, Schwald M, Aubry JM, Bertschy G 2005 Low brain-derived neurotrophic factor (BDNF) levels in serum of depressed patients probably results from lowered platelet BDNF release unrelated to platelet reactivity. Biol Psychiatry 57:1068-1072

11. Radka SF, Holst PA, Fritsche M, Altar CA 1996 Presence of brain-derived neurotrophic factor in brain and human and rat but not mouse serum detected by a sensitive and specific immunoassay. Brain Res 709:122-301

12. Nakahashi T, Fujimura H, Altar CA, Li J, Kambayashi J, Tandon NN, Sun B 2000 Vascular endothelial cells synthesize and secrete brain-derived neurotrophic factor. FEBS Lett 470:113-117 
13. Noga O, Englmann C, Hanf G, Grutzkau A, Seybold J, Kunkel G 2003 The production, storage and release of the neurotrophins nerve growth factor, brainderived neurotrophic factor and neurotrophin-3 by human peripheral eosinophils in allergics non-allergics. Clin Exp Allergy 33:649-654

14. Pan W, Banks WA, Fasold MB, Bluth J, Kastin AJ 1998 Transport of brain-derived neurotrophic factor across the blood-brain barrier. Neuropharmacology 37:1553-1561

15. Laterra J, Goldstein GW 2004 Development of the blood-brain barrier. In: Polin RA Fox WW, Abman SH (eds) Fetal and Neonatal Physiology. WB Saunders, Philadelphia, pp 1699-1706

16. Pan W, Banks WA, Kastin AJ 1998 Permeability of the blood-brain barrier to neurotrophins. Brain Res 788:87-94

17. Karege F, Schwald M, Cisse M 2002 Postnatal developmental profile of brainderived neurotrophic factor in rat brain and platelets. Neurosci Lett 328:261-264

18. Kim H, Li Q, Hempstead BL, Madri JA 2004 Paracrine and autocrine functions of brain-derived neurotrophic factor (BDNF) and nerve growth factor (NGF) in brainderived endothelial cells. J Biol Chem 279:33538-33546

19. Calle M, Wang L, Kuijpers FJ, Cruijsen PM, Arckens L, Roubos EW 2006 Brain-derived neurotrophic factor in the brain of Xenopus laevis may act as a pituitary neurohormone together with mesotocin. J Neuroendocrinol 18:454-465

20. Seifer DB, Feng B, Shelden RM, Chen S, Dreyfus CF 2002 Brain-derived neurotrophic factor: a novel human ovarian follicular protein. J Clin Endocrinol Metab $87: 655-659$

21. Binder DK, Scharfman HE 2004 Brain-derived neurotrophic factor. Growth Factors 22:123-13

22. Hanyu O, Yamatani K, Ikarashi T, Soda S, Maruyama S, Kamimura T, Kaneko S, Hirayama S, Suzuki K, Nakagawa O, Nawa H, Aizawa Y 2003 Brain-derived neurotrophic factor modulates glucagon secretion from pancreatic alpha cells: its contribution to glucose metabolism. Diabetes Obes Metab 5:27-37

23. Hu Y, Wang YD, Guo T, Wei WN, Sun CY, Zhang L, Huang J 2007 Identification of brain-derived neurotrophic factor as a novel angiogenic protein in multiple myeloma. Cancer Genet Cytogenet 178:1-10

24. Pillai A 2008 Brain-derived neurotropic factor/TrkB signaling in the pathogenesi and novel pharmacotherapy of schizophrenia. Neurosignals 16:183-193

25. Noga O, Hanf G, Schaper C, O'Connor A, Kunkel G 2001 The influence of inhalative corticosteroids on circulating Nerve Growth Factor, Brain-Derived Neurotrophic Factor and Neurotrophin-3 in allergic asthmatics. Clin Exp Allergy 31:1906-1912

26. Kim TS, Kim DJ, Lee H, Kim YK 2007 Increased plasma brain-derived neurotrophic factor levels in chronic smokers following unaided smoking cessation. Neurosci Let 423:53-57

27. Wu YW, Colford JM Jr 2000 Chorioamnionitis as a risk factor for cerebral palsy: a meta-analysis. JAMA 284:1417-1424

28. Roberts D, Dalziel S 2006 Antenatal corticosteroids for accelerating fetal lung maturation for women at risk of preterm birth. Cochrane Database Syst Rev 3:CD004454

29. Schmidt B, Asztalos EV, Roberts RS, Robertson CM, Sauve RS, Whitfield MF 2003 Impact of bronchopulmonary dysplasia, brain injury, and severe retinopathy on the outcome of extremely low-birth-weight infants at 18 months: results from the trial of indomethacin prophylaxis in preterms. JAMA 289:1124-1129

30. Stoll BJ, Hansen NI, Adams-Chapman I, Fanaroff AA, Hintz SR, Vohr B, Higgin RD 2004 Neurodevelopmental and growth impairment among extremely low-birthweight infants with neonatal infection. JAMA 292:2357-2365

31. Inder TE, Huppi PS, Warfield S, Kikinis R, Zientara GP, Barnes PD, Jolesz F, Volpe JJ 1999 Periventricular white matter injury in the premature infant is followed by reduced cerebral cortical gray matter volume at term. Ann Neurol 46:755-760

32. Huppi PS, Warfield S, Kikinis R, Barnes PD, Zientara GP, Jolesz FA, Tsuji MK, Volpe JJ 1998 Quantitative magnetic resonance imaging of brain development in premature and mature newborns. Ann Neurol 43:224-235

33. Mewes AU, Huppi PS, Als H, Rybicki FJ, Inder TE, McAnulty GB, Mulkern RV, Robertson RL, Rivkin MJ, Warfield SK 2006 Regional brain development in serial magnetic resonance imaging of low-risk preterm infants. Pediatrics 118:23-33

34. Malamitsi-Puchner A, Economou E, Rigopoulou O, Boutsikou T 2004 Perinatal changes of brain-derived neurotrophic factor in pre- and fullterm neonates. Early Hum Dev 76:17-22

35. Nikolaou KE, Malamitsi-Puchner A, Boutsikou T, Economou E, Boutsikou M, Puchner KP, Baka S, Hassiakos D 2006 The varying patterns of neurotrophin changes in the perinatal period. Ann N Y Acad Sci 1092:426-433

36. Chouthai NS, Sampers J, Desai N, Smith GM 2003 Changes in neurotrophin levels in umbilical cord blood from infants with different gestational ages and clinical conditions. Pediatr Res 53:965-969

37. Korhonen L, Riikonen R, Nawa H, Lindholm D 1998 Brain derived neurotrophic factor is increased in cerebrospinal fluid of children suffering from asphyxia Neurosci Lett 240:151-154

38. Chiaretti A, Antonelli A, Piastra M, Genovese O, Polidori G, Aloe L 2004 Expression of neurotrophic factors in cerebrospinal fluid and plasma of children with viral and bacterial meningoencephalitis. Acta Paediatr 93:1178-1184

39. Gilmore JH, Jarskog LF, Vadlamudi S 2003 Maternal infection regulates BDNF and NGF expression in fetal and neonatal brain and maternal-fetal unit of the rat J Neuroimmunol 138:49-55

40. Marx CE, Vance BJ, Jarskog LF, Chescheir NC, Gilmore JH 1999 Nerve growth factor, brain-derived neurotrophic factor, and neurotrophin-3 levels in human amniotic fluid. Am J Obstet Gynecol 181:1225-1230

41. Murphy BP, Inder TE, Huppi PS, Warfield S, Zientara GP, Kikinis R, Jolesz FA, Volpe JJ 2001 Impaired cerebral cortical gray matter growth after treatment with dexamethasone for neonatal chronic lung disease. Pediatrics 107:217-221
42. Gibbs RS, Blanco JD, St Clair PJ, Castaneda YS 1982 Quantitative bacteriology of amniotic fluid from women with clinical intraamniotic infection at term. J Infect Dis $145: 1-8$

43. ACOG 2007 Practice Bulletin No. 80: premature rupture of membranes. Obstet Gynecol 109:1007-1019

44. ACOG 2008 Antenatal corticosteroid therapy for fetal maturation. Obstet Gyneco 111:805-807

45. Ballard JL, Khoury JC, Wedig K, Wang L, Eilers-Walsman BL, Lipp R 1991 New Ballard Score, expanded to include extremely premature infants. J Pediatr 119:417-423

46. Campbell S, Newman GB 1971 Growth of the fetal biparietal diameter during normal pregnancy. J Obstet Gynaecol Br Commonw 78:513-519

47. Papile LA, Burstein J, Burstein R, Koffler H 1978 Incidence and evolution of subependymal and intraventricular hemorrhage: a study of infants with birth weights less than 1,500 gm. J Pediatr 92:529-534

48. Jobe AH, Bancalari E 2001 Bronchopulmonary dysplasia. Am J Respir Crit Care Med 163:1723-1729

49. Bell MJ, Ternberg JL, Feigin RD, Keating JP, Marshall R, Barton L, Brotherton T 1978 Neonatal necrotizing enterocolitis. Therapeutic decisions based upon clinica staging. Ann Surg 187:1-7

50. ICROP 2005 The international classification of Retinopathy of Prematurity revisited Arch Opthalmol 123:991-999

51. Rojas Vega S, Struder HK, Vera Wahrmann B, Schmidt A, Bloch W, Hollmann W 2006 Acute BDNF and cortical response to low intensity exercise and following ramp incremental exercise to exhaustion in humans. Brain Res 1121:59-65

52. Prusa AR, Marton E, Rosner M, Bettelheim D, Lubec G, Pollack A, Bernaschek G, Hengstschlager M 2004 Neurogenic cells in human amniotic fluid. Am J Obste Gynecol 191:309-314

53. Lommatzsch M, Hornych K, Zingler C, Schuff-Werner P, Hoppner J, Virchow JC 2006 Maternal serum concentrations of BDNF and depression in the perinatal period. Psychoneuroendocrinology 31:388-394

54. Uchida S, Inanaga Y, Kobayashi M, Hurukawa S, Araie M, Sakuragawa N 2000 Neurotrophic function of conditioned medium from human amniotic epithelial cells. J Neurosci Res 62:585-590

55. Fan CG, Zhang QJ, Tang FW, Han ZB, Wang GS, Han ZC 2005 Human umbilica cord blood cells express neurotrophic factors. Neurosci Lett 380:322-325

56. Jacobsen JP, Mork A 2006 Chronic corticosterone decreases brain-derived neurotrophic factor (BDNF) mRNA and protein in the hippocampus, but not in the frontal cortex, of the rat. Brain Res 1110:221-225

57. Prickaerts J, van den Hove DL, Fierens FL, Kia HK, Lenaerts I, Steckler T 2006 Chronic corticosterone manipulations in mice affect brain cell proliferation rates, but only partly affect BDNF protein levels. Neurosci Lett 396:12-16

58. Barbany G, Persson H 1992 Regulation of Neurotrophin mRNA expression in the rat brain by glucocorticoids. Eur J Neurosci 4:396-403

59. Yang JT, Chang CN, Lee TH, Hsu JC, Lin TN, Hsu YH, Hsieh Wu J 2002 Effect of dexamethasone on the expression of brain-derived neurotrophic factor and neurotrophin-3 messenger ribonucleic acids after forebrain ischemia in the rat. Crit Care Med 30:913-918

60. Murer MG, Yan Q, Raisman-Vozari R 2001 Brain-derived neurotrophic factor in the control human brain, and in Alzheimer's disease and Parkinson's disease. Prog Neurobiol 63:71-124

61. Ohmiya M, Shudai T, Nitta A, Nomoto H, Furukawa Y, Furukawa S 2002 Brainderived neurotrophic factor alters cell migration of particular progenitors in the developing mouse cerebral cortex. Neurosci Lett 317:21-24

62. Ringstedt T, Linnarsson S, Wagner J, Lendahl U, Kokaia Z, Arenas E, Ernfors P, Ibanez CF 1998 BDNF regulates reelin expression and Cajal-Retzius cell development in the cerebral cortex. Neuron 21:305-315

63. Bekinschtein P, Cammarota M, Izquierdo I, Medina JH 2008 BDNF and memory formation and storage. Neuroscientist 14:147-156

64. Caleo M, Maffei L 2002 Neurotrophins and plasticity in the visual cortex. Neuroscientist 8:52-61

65. Nag TC, Wadhwa S 1999 Neurotrophin receptors (Trk A, Trk B, and Trk C) in the developing and adult human retina. Brain Res Dev Brain Res 117:179-189

66. Chen J, Smith LE 2007 Retinopathy of prematurity. Angiogenesis 10:133-140

67. Kwinta P, Bik-Multanowski M, Mitkowska Z, Tomasik T, Pietrzyk JJ 2008 The clinical role of vascular endothelial growth factor (VEGF) system in the pathogen esis of retinopathy of prematurity. Graefes Arch Clin Exp Ophthalmol 246:14671475

68. Pieh C, Agostini H, Buschbeck C, Kruger M, Schulte-Monting J, Zirrgiebel U, Drevs J, Lagreze WA 2008 VEGF-A, VEGFR-1, VEGFR-2 and Tie2 levels in plasma of premature infants: relationship to retinopathy of prematurity. $\mathrm{Br} \mathrm{J}$ Ophthalmo 92:689-693

69. Kermani P, Hempstead B 2007 Brain-derived neurotrophic factor: a newly described mediator of angiogenesis. Trends Cardiovasc Med 17:140-143

70. Nakamura K, Martin KC, Jackson JK, Beppu K, Woo CW, Thiele CJ 2006 Brain-derived neurotrophic factor activation of TrkB induces vascular endothelia growth factor expression via hypoxia-inducible factor-1alpha in neuroblastoma cells. Cancer Res 66:4249-4255

71. Burton CL, Chatterjee D, Chatterjee-Chakraborty M, Lovic V, Grella SL, Steiner M, Fleming AS 2007 Prenatal restraint stress and motherless rearing disrupts expression of plasticity markers and stress-induced corticosterone release in adult female Sprague-Dawley rats. Brain Res 1158:28-38

72. Van den Hove DL, Steinbusch HW, Scheepens A, Van de Berg WD, Kooiman LA Boosten BJ, Prickaerts J, Blanco CE 2006 Prenatal stress and neonatal rat brain development. Neuroscience 137:145-155 